Article

\title{
On the Influence of the Ammonium Nitrate(V) Provenance on Its Usefulness for the Manufacture of ANFO Type Explosives
}

\author{
Andrzej Biessikirski ${ }^{1, *} \mathbb{1}$, Łukasz Kuterasiński ${ }^{2}{ }^{\mathbb{D}}$, Michał Dworzak ${ }^{1}$, Michał Twardosz ${ }^{1}$, \\ Maciej Tatko ${ }^{3}$ and Bogna Daria Napruszewska ${ }^{2}$ \\ 1 Faculty of Mining and Geoengineering, AGH University of Science and Technology, Al. Mickiewicza 30, \\ 30-059 Kraków, Poland; dworzak@agh.edu.pl (M.D.); michaltw@agh.edu.pl (M.T.) \\ 2 Jerzy Haber Institute of Catalysis and Surface Chemistry, Polish Academy of Sciences, ul. Niezapominajek 8, \\ 30-239 Kraków, Poland; nckutera@cyf-kr.edu.pl (Ł.K.); ncnaprus@cyf-kr.edu.pl (B.D.N.) \\ 3 Fluorochemika Poland sp. z o.o., ul. Kwiatkowskiego 8, 33-101 Tarnów, Poland; tatko.maciek@gmail.com \\ * Correspondence: abiess@agh.edu.pl; Tel.: +48-12-617-20-70
}

Received: 15 August 2020; Accepted: 18 September 2020; Published: 21 September 2020

check for updates

\begin{abstract}
Ammonium nitrate fuel oil (ANFO) samples based on fertilizer (AN-F) and ammonium nitrate porous prill (AN-PP) were studied. Tests were carried out using both a thermogravimetric analyzer and differential scanning calorimetry (TGA/DSC). Furthermore, the scanning electron microscopy analysis (SEM) of ammonium nitrate(V) (AN) concerning either their surface or cross-section was performed. Based on the SEM results, it was shown that the surface of AN-F grains was flat and slightly deformed, while the AN-PP surface was wrinkled and deformed. Furthermore, the various steps of thermogravimetric process exhibited continuous AN phase transition according to precise temperatures. From TGA analysis, a significant mass loss was found as a result of ANFO decomposition. Direct comparison of SEM and TGA/DCS data led to the conclusion that ANFO based on AN-F was characterized by lower absorption of FO in contrast to AN-PP.
\end{abstract}

Keywords: ammonium nitrate (V); ANFO; morphology; thermal decomposition; TGA

\section{Introduction}

Ammonium nitrate(V) (AN) is a chemical compound, which was synthesized by Glauber in 1654 by the mixing of ammonium carbonate with nitric acid [1]. Currently, ammonium nitrate(V) is usually obtained via a chemical reaction between nitric acid with ammonia. The result of this synthesis is a concentrated aqueous AN solution (83.0-87.0\%), which is further subjected to the evaporation process to obtain a more concentrated AN solution (ca. of $97.0 \%$ of AN) [2]. Depending on the final product application (agriculture or explosive industry), AN solution is subsequently converted to solid form by prilling or granulation. In both cases, the synthesized product is in the form of a spherical prill or granule and differs with size and physical properties (e.g., porosity, mechanical resistance, etc.). It can be applied as an oxygen component in the explosive composition. Landucci et al. indicated that ammonium nitrate fuel oil (ANFO), based on the fertilizer grade of AN (AN-F), was less efficient and was characterized by a lower void fraction in comparison to the ammonium nitrate porous prill (AN-PP) counterpart [3]. Moreover, due to the European regulation [4], AN-F requires modification to be introduced to the market. However, despite this fact, it is this type of AN [3] that is usually used as the oxygen component in home-made explosives.

One of the crucial parameters determining AN stability and detonation behavior is the wettability of AN. According to Kwok and Jones, AN wettability is influenced by several factors, e.g., porosity or the prill surface area [5]. 
The morphology of the ammonium nitrate has been studied by [6-13]. Biessikirski et al. reported that the surface of ammonium nitrate porous prill (AN-PP) was highly deformed and was characterized by the presence of numerous wrinkles, which influenced the absorption index [6]. Viktorov et al. analyzed the morphology of AN-PP, which was manufactured in Russia [7]. Moreover, they presented the formation of the prill surface during the heating process. Lotspeich and Petr reported that fertilizer based ammonium nitrate (AN-F) possessed pumice-like surface [8]. In turn, in the cross-section of whole AN-PP prill, the presence of wrinkles was found [8]. Elzaki and Zhang investigated the influence of the coating on the AN morphology [9]. It was found the presence of numerous hollows and cracks over pure AN grains surface. The addition of cetyl alcohol caused smoothening and agglomeration of AN surface [9]. Biessikirski and Kuterasinski recommended the application of AN-PP as the ANFO's oxygen component due to its surface properties [10]. Miyake et al. indicated that in case of the same particle diameter ANFO's velocity of detonation increased with the decrease of the mode pore diameter, and in case of the same pole volume velocity of detonation increased with the decrease of the particle diameter [11] and Rao et al. evaluated ANFO's explosive characteristics, caking, rheology and friability based on the scanning electron microscopic [12].

Despite the numerous characterization methods concerning porous materials, a shortage of information on thermal properties of ANFO was found. The available literature is dedicated to the thermal decomposition of pure AN [13-15]. Berthelot indicated that AN could undergo seven different decomposition reaction paths, resulting in products and thermodynamic conditions. Barbauskas and Legett, as well as Chaturvedi and Dave, evidenced that AN occurs in at least five different crystal forms $[14,15]$. It must be highlighted that both AN physical integrity and chemical behavior may be influenced. The chemical integrity can be disturbed when the transformation of phase III to phase II takes place at the transition temperature. The physical integrity of $\mathrm{AN}$ is influenced by the moisture, pressure and temperature [16].

Moreover, the role of contaminants, e.g., pyrite [17,18], sodium sulfate [19,20], sodium bicarbonate, potassium carbonate and ammonium sulfate [21] on thermal decomposition and AN stability was also reported. It should be mentioned that due to the possible AN caking, manufactures add, e.g., magnesium nitrate to the AN in order to inhibit the phase IV $\rightarrow$ phase III transition [15]. Oxley et al. concluded that several additives stabilize AN and might be acceptable in fertilizer formulations, however, these formulations have not shown to be non-detonatable [22]. In addition, Kwok and Jones made an evaluation of adsorption capacity and porosity of variously prepared samples of AN (mini or porous) immersed in octane [5].

This research aims to study thermal decomposition properties of AN-F, AN-PP and non-ideal explosives that were obtained based on studied AN samples. Furthermore, the morphology studies (utilizing SEM) allow for explaining of how AN structure affects the absorption index.

\section{Materials and Methods}

The Yara's International A SA produced AN-PP no. 8 (AN-PP8). AN was characterized by a density of $820 \mathrm{~kg} \cdot \mathrm{m}^{-3}$. The prill diameter was in the range of $1-2 \mathrm{~mm}$. The nitrogen content was ca. of $35.0 \%$. The absorption index was ca. $12.0 \%$.

The Yara's International A SA manufactured AN-PP no 7 (AN-PP7). AN density was $720 \mathrm{~kg} \cdot \mathrm{m}^{-3}$. The prill diameter was $<1 \mathrm{~mm}$. The grade of AN-PP was 35.0\% nitrogen. The absorption index was $14.0 \%$.

"Anwil" S.A provided AN-F. It contained 34.0\% nitrogen, equally in the form of nitrate and ammoniacal nitrogen, as well as $0.2 \%$ magnesium in the form of magnesium nitrate. The prill size was in the range of 1-3 mm, AN-F bulk density was ca. of $920-1000 \mathrm{~kg} \cdot \mathrm{m}^{-3}$. The absorption index was $8.0 \%$.

Fuel oil (FO) was a wide-range sample, consisting of linear hydrocarbons and manufactured by the Silesia Oil Sp. z.o.o. strictly for the blasting industry. The sample density and kinetic viscosity 
were $873.2 \mathrm{~kg} \cdot \mathrm{m}^{-3}$ and $13.6 \mathrm{~mm}^{2} \cdot \mathrm{s}^{-1}$, respectively. Detailed low-temperature properties have been presented in [23].

Three types of samples have been prepared: pure AN, wetted AN with FO and wetted AN with the addition of $\mathrm{FO}$ in excess.

All AN-based samples wetted with FO were prepared by the mixing of AN-PP7 or AN-PP8 or AN-F with fuel oil according to the weight ratio of 94.5:5.5. Blending was performed for $20 \mathrm{~min}$ at $250 \mathrm{rpm}$ by a laboratory mixer.

All AN-based samples wetted with the excess of FO were prepared by the mixing of AN-PP7 or AN-PP8 or AN-F with fuel oil according to the weight ratio of 90.0:10.0. Blending was performed for $20 \mathrm{~min}$ at $250 \mathrm{rpm}$ by a laboratory mixer. The excess of the fuel oil in ANFO composition was $4.5 \%$.

The differential scanning calorimetry (DSC) and thermogravimetry (TG) analyses were performed using NETZSCH STA 409 PC/PG with a heating ramp of $10^{\circ} \mathrm{C} \cdot \mathrm{min}^{-1}$.

Temperature controlled desorption of $\mathrm{FO}$ from the surface of AN prill was carried out at either 20-130 ${ }^{\circ} \mathrm{C}$ (first data set) or $20-700{ }^{\circ} \mathrm{C}$ (second data set only for AN blended with the FO in excess). All studied samples were kept under an airflow of $30 \mathrm{~mL} \cdot \mathrm{min}^{-1}$ both in the furnace and balance chamber. The air was applied to stimulate detonation conditions. For each experiment, the prepared sample was placed in the DSC aluminum pan using a spatula. The mass of each sample was $20 \mathrm{mg}$. The baseline of the TG was confirmed by the application of the same heating profile for the empty pan. The TG drift was ca $5 \mu \mathrm{g}$ which represents 0.02 mass $\%$.

Scanning electron microscopy analyses (SEM) of pure AN and non-ideal explosive samples were performed using Nova NanoSEM 200 from FEI Europe (5-18 keV). A microscope allows to operate under high or low vacuum. Micrographs were taken in low vacuum (ca. $60 \mathrm{~Pa}$ ) and under the electron beam voltage of $10 \mathrm{kV}$. The samples were mounted to holders by double-sided conductive vacuum compatible carbon tape. Before the analysis, AN samples were dried and coated with a carbon layer. The morphology results of prepared samples were presented as SEM images in Figures 1 and 2.

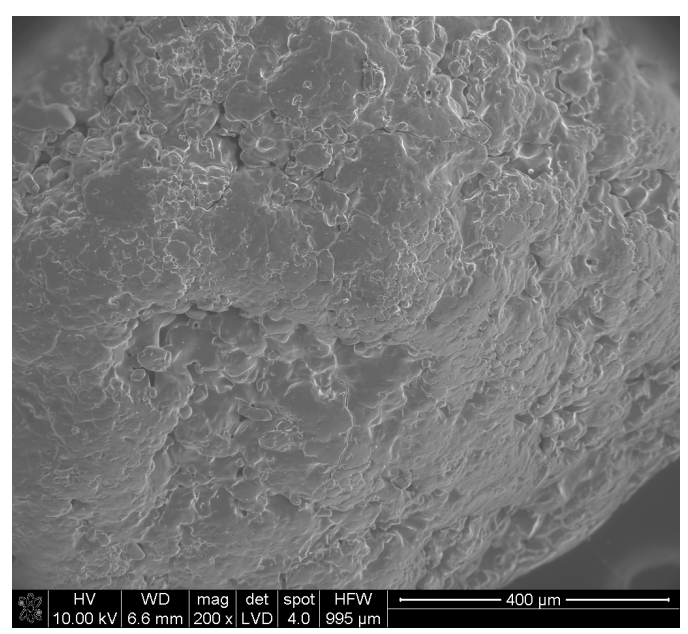

(a)

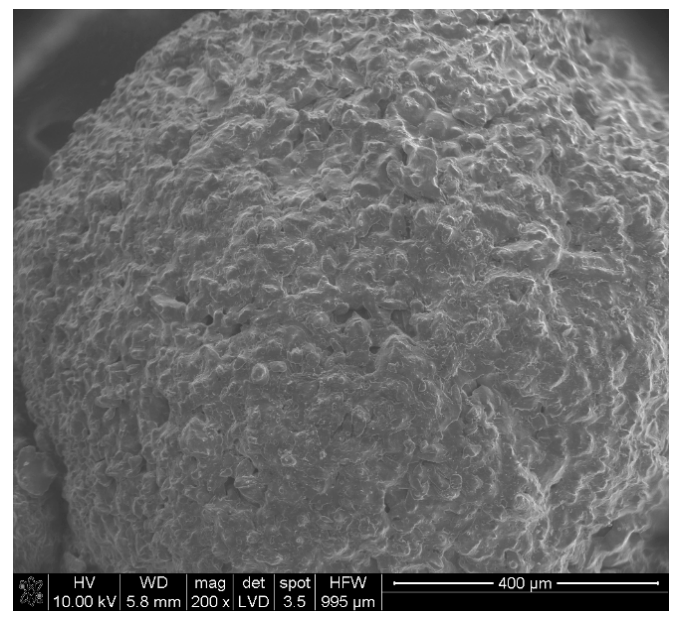

(b)

Figure 1. Cont. 


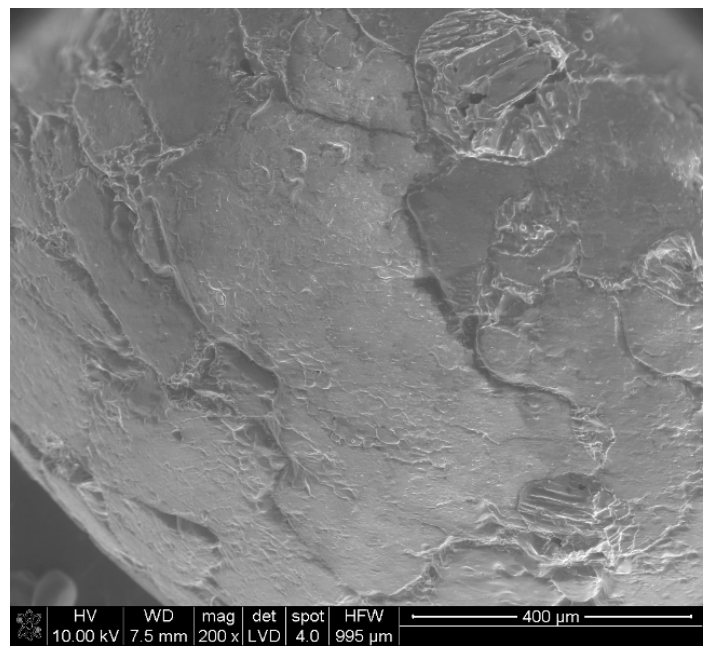

(c)

Figure 1. Scanning electron microscopy (SEM) images of prill at a magnification of 200×: (a) AN-PP8; (b) AN-PP7; (c) AN-F.

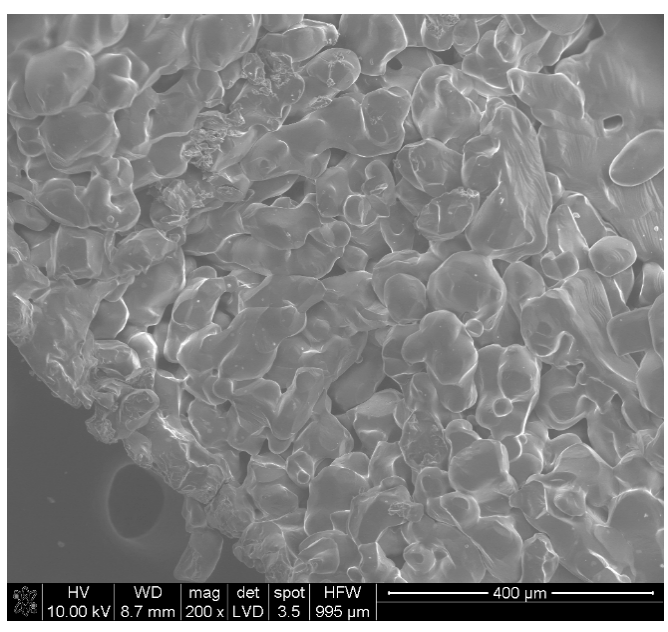

(a)

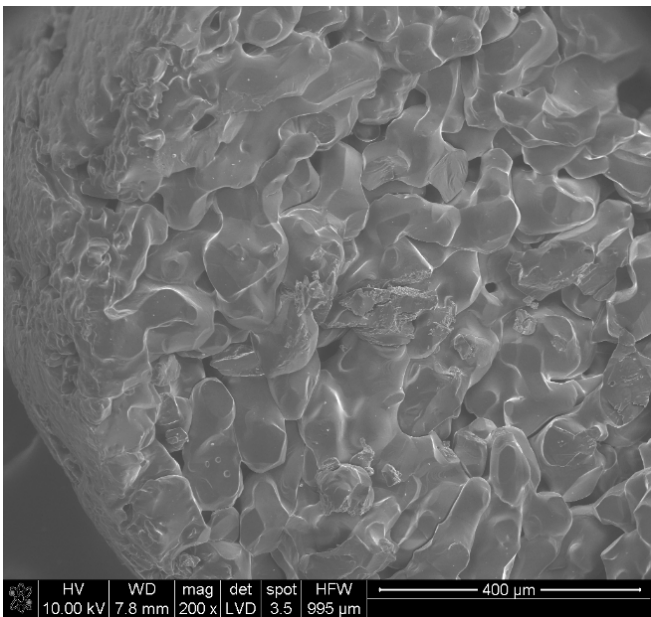

(b)

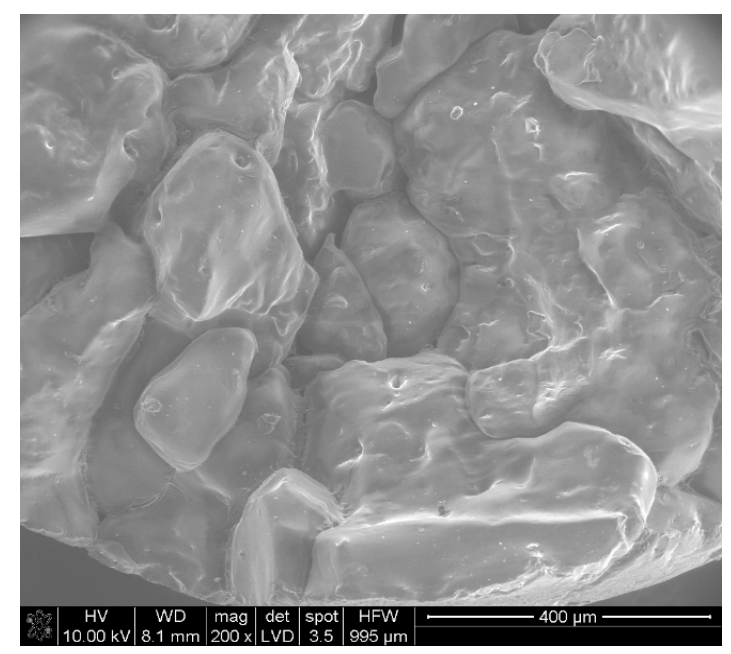

(c)

Figure 2. SEM images of cross-sectioned prill surface at a magnification of 200x: (a) AN-PP8; (b) AN-PP7; (c) AN-F. 


\section{Results and Discussion}

SEM analysis has indicated the presence of steam-like pathway on the crystal surfaces of the AN-PP7 and AN-PP8 prills. Numerous surface deformations on both AN-PP7 and AN-PP8 prills were observed. In the case of AN-PP8 prill, the appearance of a central cavity was detected (bottom-left corner of Figure 1a). The same cavity is apparent on the surface of AN-PP7 (bottom-left edge of the Figure 1b). This "air pocket" was probably formed due to the occurrence of stresses, which were generated as a result of the AN solidification $[7,24]$ Obtained results are in accordance with paper [7], in which Viktorov et al. pointed out that the surface around the mount of the shrinkage cavity was similar to the surface of the prill and depended on the AN provenance. Furthermore, based on Figure 1a,b, the co-existence of variously distributed cracks with face opening over the surface, both AN-PP7 and AN-PP8 may be concluded. Observed differences between AN-PP7 and AN-PP8 SEM images referred to the prills sizes and the multiplicity of the surface deformations. In the case of AN-PP7, the prill size was smaller, and the number of structural-deformations was higher in comparison with AN-PP8.

The AN-F granule was rather flat with a few surface deformations and cracks (Figure 1c). Furthermore, a small number of macropores was observed. The appearance of distortions present over found surfaces suggests low absorption of FO within AN-F structure.

To investigate the inert morphology structure of both AN-PP and AN-F crystals, cross-section SEM micrographs were given in Figure 2.

Cross-sectioned SEM images of AN-F and AN-PP have revealed that AN-F crystals were longitudinal, complex and rather flat, Figure 2c. A few surface deformations of wrinkle-like type were observed. The co-existence of inter-crystalline channel-shape spaces were also found. The appearance of the cross-sectioned crystal of the AN-F is similar to a pumice stone. No channel entries were visible on the crystalline surface. This observation may be a result of the solidification process, which was occurring during the production of the AN-F [8].

The cross-sections of the AN-PP have revealed the presence of complex wrinkle-shaped structures and inter-crystalline spaces. The air gaps were longitudinal towards prill core (Figure 2a,b). Small deformations of crack type were also visible on the cross-sectioned crystal surface. Obtained results are in line with [8], where Lotspeich and Petr indicated that explosive-grade prills were characterized by the presence of steam-like pathways in the whole volume of the prill.

In order to establish AN and non-ideal explosive thermal decomposition, as well as in order to determine the correlation between AN morphology and the ability of FO absorption, thermal analysis has been performed. The TG mass loss, as well as DSC heat effects, were measured for various types of AN-based samples. The TG/DSC results were presented in Table 1 and Figures 3-9.

Table 1. Differential scanning calorimetry (DSC) and thermogravimetry (TG) results of AN-based samples.

\begin{tabular}{cccc}
\hline Sample & $\begin{array}{c}\text { The Temperature of the } \\
\text { First DSC Peak }\end{array}$ & $\begin{array}{c}\text { The Temperature of the } \\
\text { Second DSC Peak }\end{array}$ & TG Mass Loss \\
\hline AN-PP7 & $59.9^{\circ} \mathrm{C}$ & None & None \\
AN-PP8 & $61.5^{\circ} \mathrm{C}$ & None & $0.15 \%$ \\
AN-F & $55.0^{\circ} \mathrm{C}$ & $95.5^{\circ} \mathrm{C}$ & $0.36 \%$ \\
AN-PP7 + FO & $60.0^{\circ} \mathrm{C}$ & None & None \\
AN-PP8 + FO & $58.5^{\circ} \mathrm{C}$ & None & $0.19 \%$ \\
AN-F + FO & $56.0^{\circ} \mathrm{C}$ & $99.0^{\circ} \mathrm{C}$ & $0.42 \%$ \\
AN-PP7 + FO excess & $60.5^{\circ} \mathrm{C}$ & $88.0-91.5^{\circ} \mathrm{C}$ & $0.23 \%$ \\
AN-PP8 + FO excess & $60.0^{\circ} \mathrm{C}$ & $92.5-94.0{ }^{\circ} \mathrm{C}$ & $0.11 \%$ \\
AN-F + FO excess & $56.5^{\circ} \mathrm{C}$ & $96.5^{\circ} \mathrm{C}$ & $0.46 \%$ \\
\hline
\end{tabular}




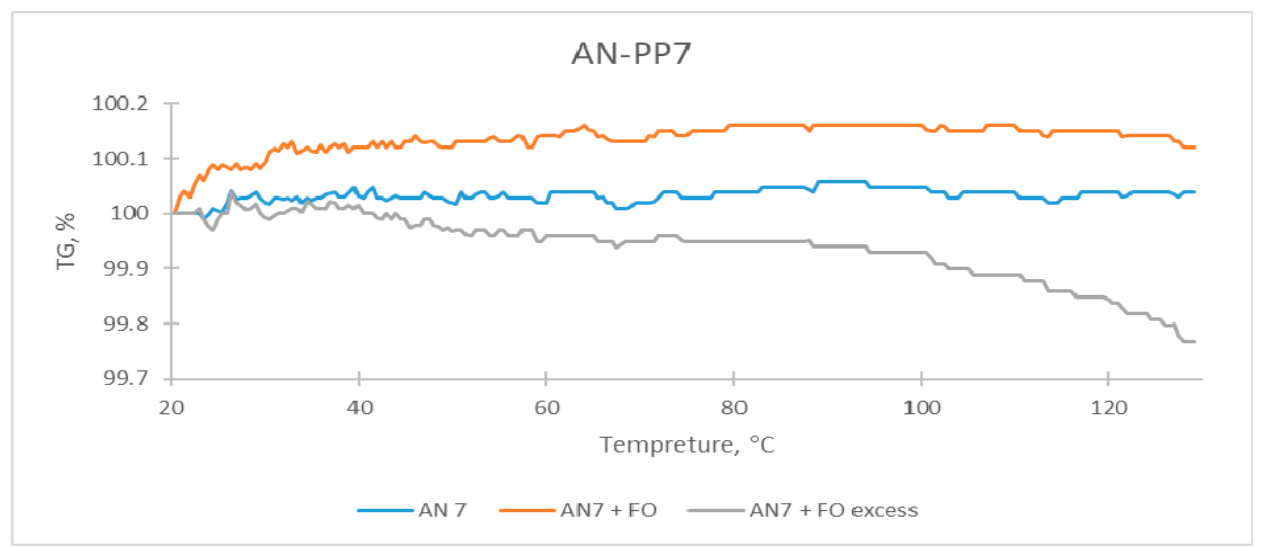

Figure 3. TG results of AN-PP7.

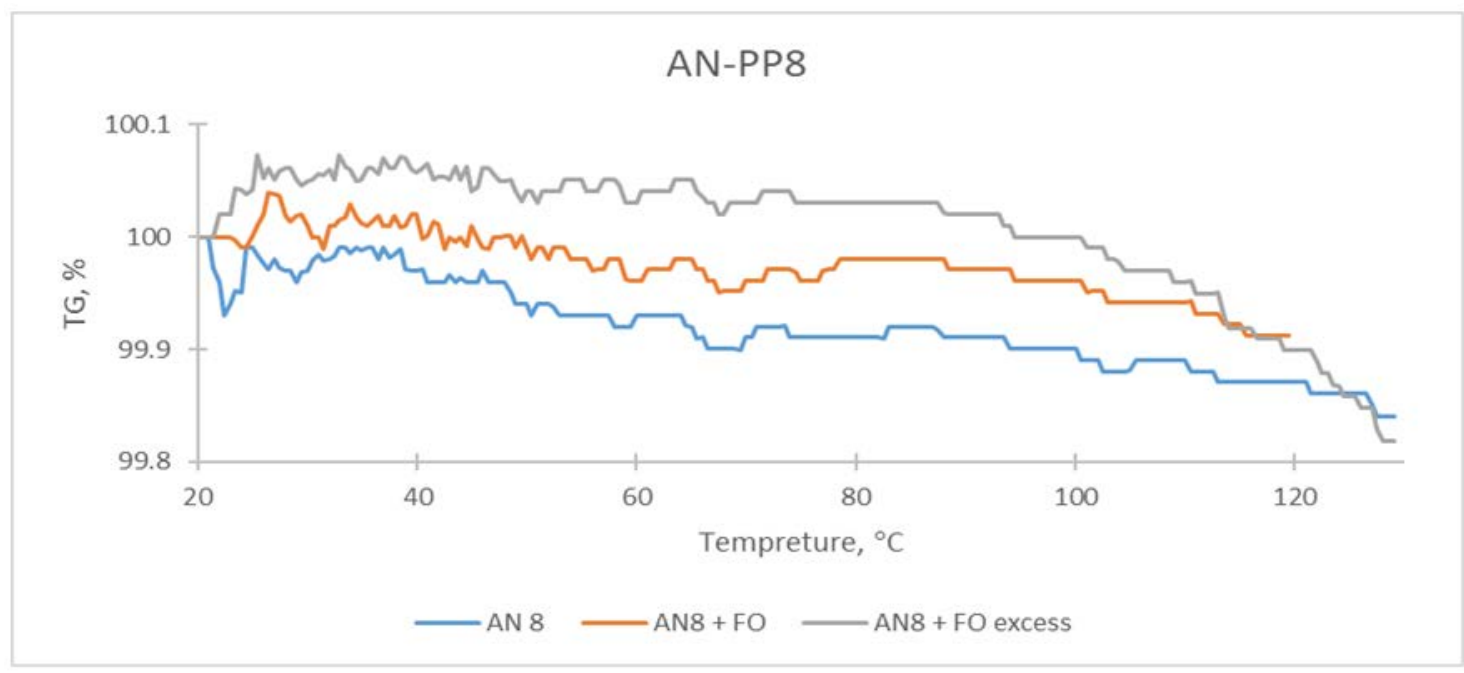

Figure 4. TG results of AN-PP8.

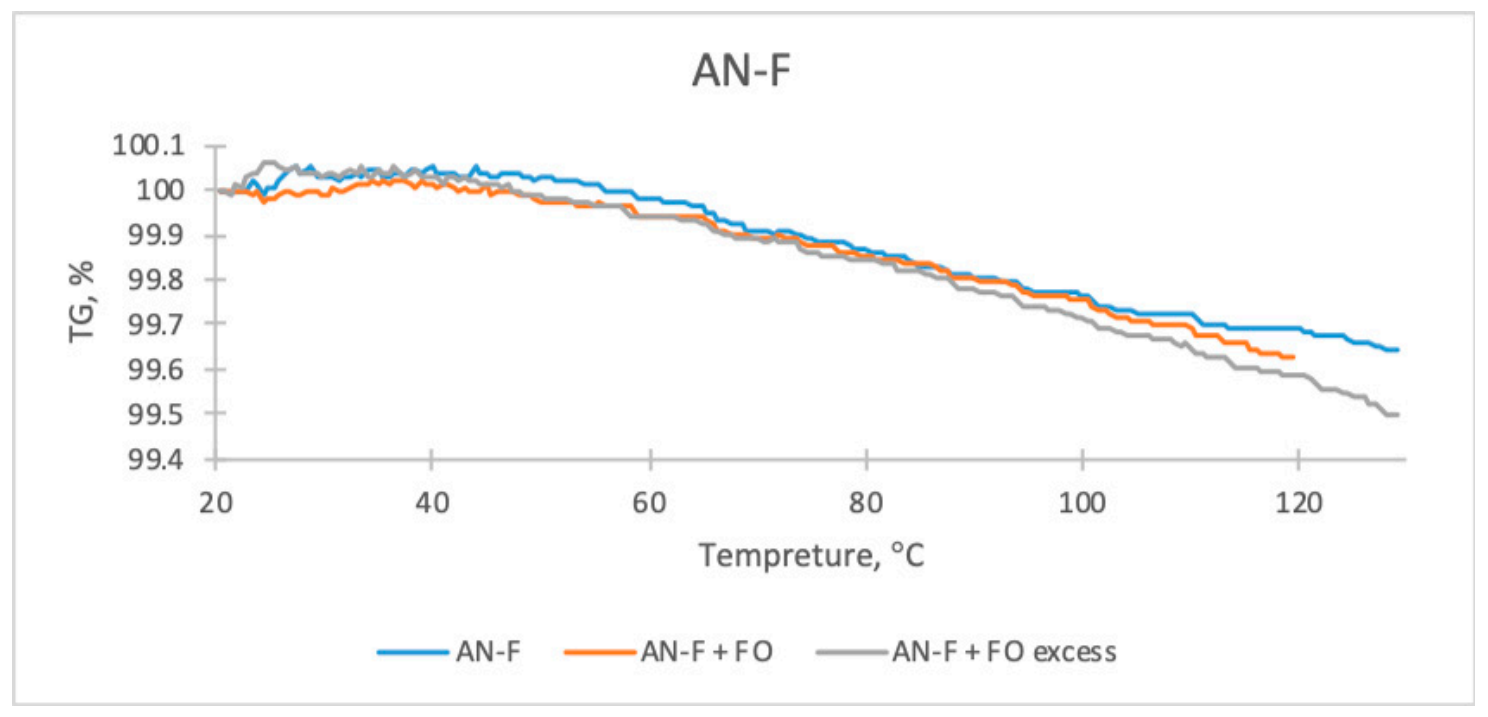

Figure 5. TG results of AN-F. 


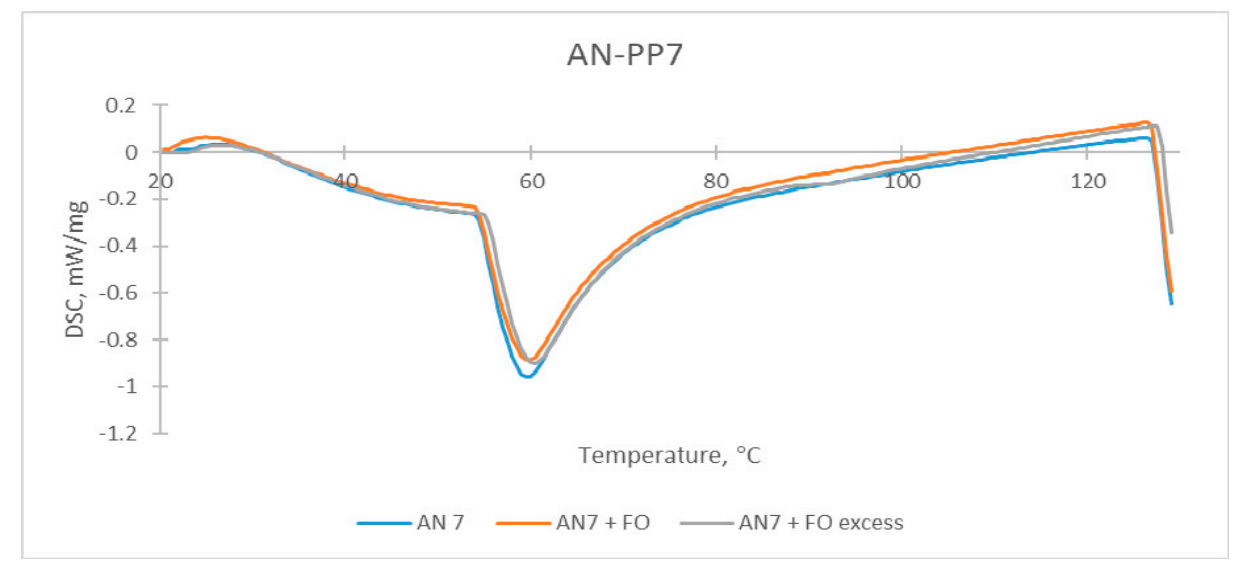

Figure 6. DSC results of AN-PP7.

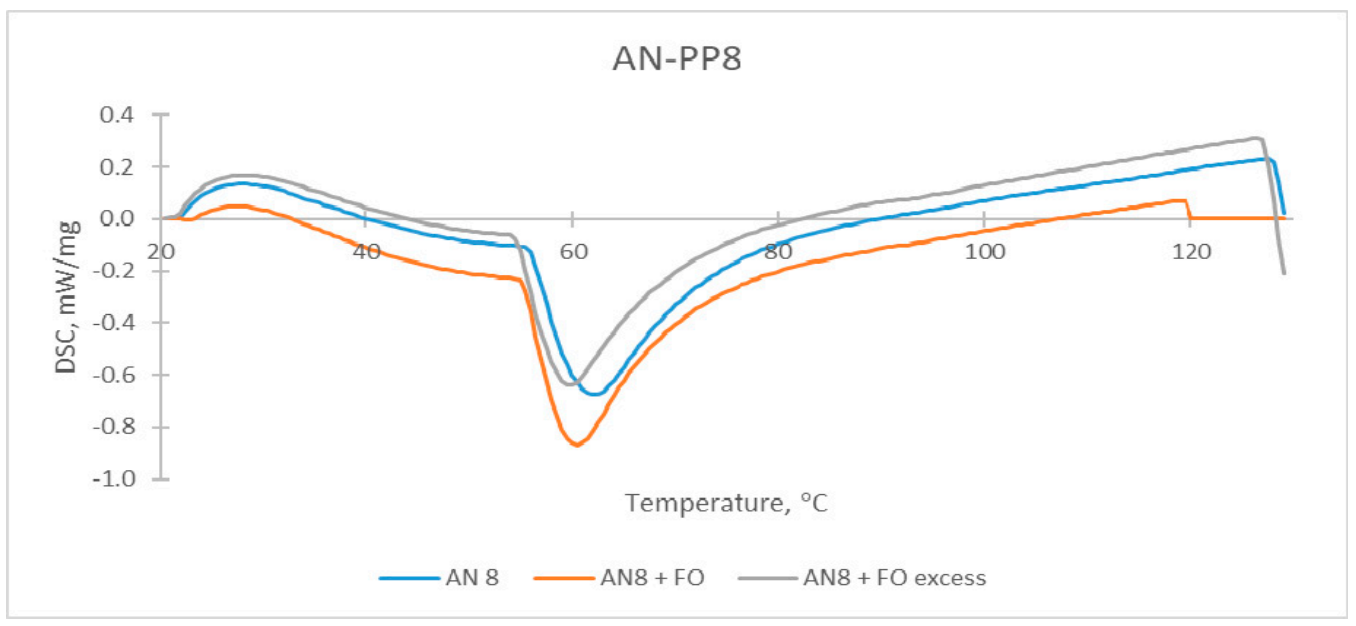

Figure 7. DSC results of AN-PP8.

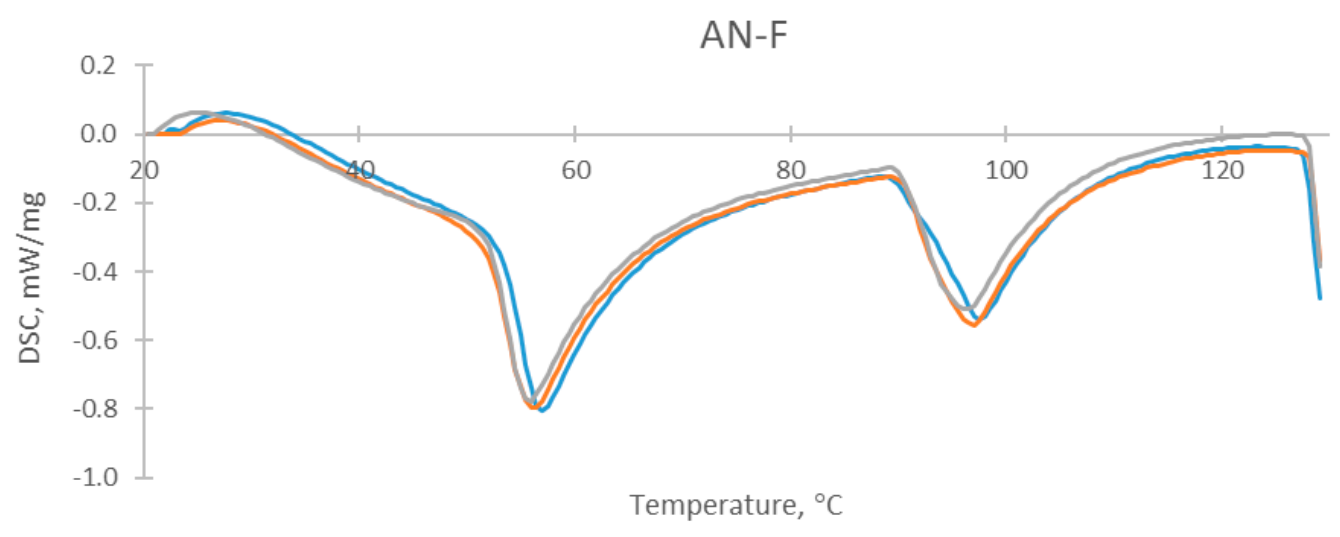

$\longrightarrow \mathrm{AN}-\mathrm{F} \longrightarrow \mathrm{AN}-\mathrm{F}+\mathrm{FO} \longrightarrow \mathrm{AN}-\mathrm{F}+\mathrm{FO}$ excess

Figure 8. DSC results of AN-F. 


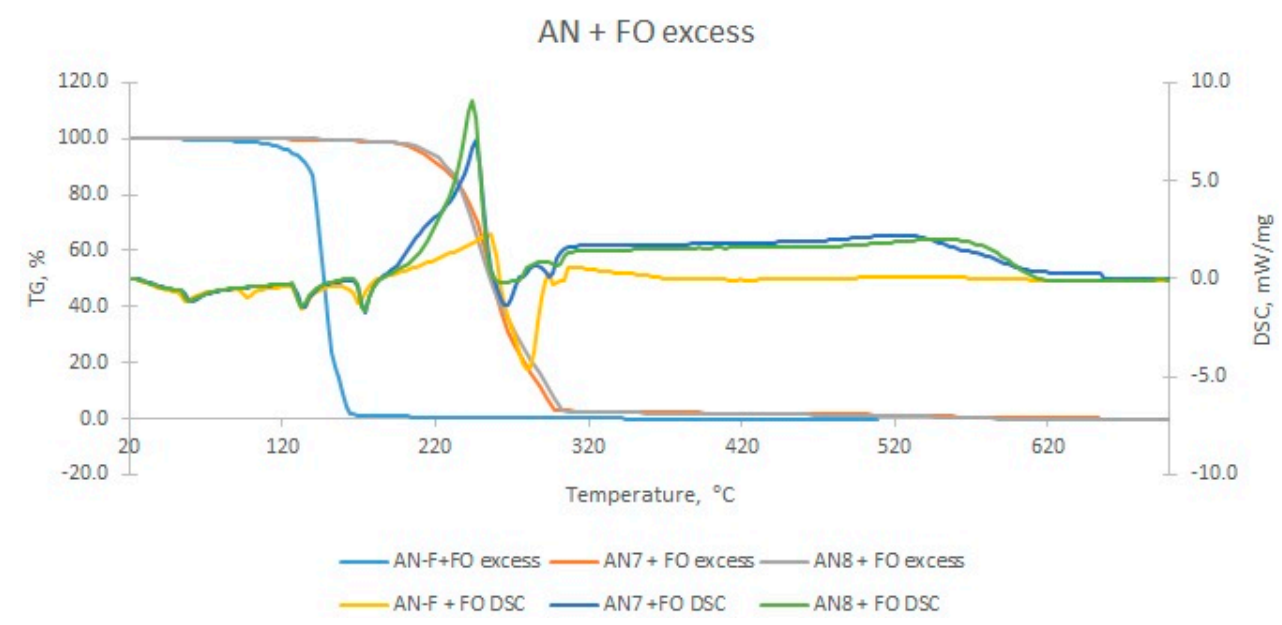

Figure 9. TG/DSC results of AN with fuel oil (FO) excess.

TG data (Figures 3-5) showed that in all cases, the interaction between FO and airflow was followed by the mass loss due to the evaporation of FO from the surface of crystalline AN. In addition, in the case of AN-PP8 and AN-F a temporary increase of the mass was observed in the temperature range of $20-50{ }^{\circ} \mathrm{C}$. This can be explained by the heating process which was conducted in the presence of the air flow. This might result with formation of the secondary products. A similar phenomenon (mass increase) was observed in the case of AN-PP7, however the temperature range was higher. Further heating resulted with a mass decrease.

Analysis of DSC data exhibited differences between AN-F, AN-PP7 and AN-PP8 samples. In the case of AN-F, the appearance of DSC curves (Figure 8) corresponded to the morphology of AN-F-based sample (less number of surface deformations), which resulted in lower adsorption ratio (ca. $8.0 \%$ ) in comparison with AN-PP7 (14.0\%) and AN-PP8 (12.0\%), respectively. For the AN-PP7 and AN-PP8 counterparts, mass loss, Figures 6-8, was not observed until the AN-PP had been immersed in excess of FO, which can be explained by the AN-PP higher adsorption ratio. In other words, the FO monolayer was stronger absorbed on the AN-PP surface, which led to the "surface supersaturation" state. That resulted in the appearance of weak forces on the phase boundaries. The appearance of weak forces led to easier desorption of FO from AN-PP surface. This phenomenon can be confirmed by the absence of the second peak in the DSC profile (Figure 8 and Table 1), as well as by a small energetic effect accompanied by the relatively high mass loss. Furthermore, only AN samples with FO excess showed the appearance of the second peak. Hence, an additional TG/DSC analysis was made in the temperature range of $20-700{ }^{\circ} \mathrm{C}$, Figure 9 .

The DSC profile indicates four endothermic peaks, Figure 9. First two signals at ca. $60^{\circ} \mathrm{C}$ and ca. $134{ }^{\circ} \mathrm{C}$ represent the crystallographic transformation of AN phase III $\rightarrow$ phase II and AN phase II $\rightarrow$ phase I, respectively [25]. Those transition temperatures may be influenced by the water content, thermal sample treatment method and the amount of impurities. In the case of AN-F-based sample, an additional peak at $91^{\circ} \mathrm{C}$ was observed. It might be explained by the presence of magnesium. The third endothermic peak at ca. $176^{\circ} \mathrm{C}$ may be assigned to the melting point of the AN. Further increase in the temperature caused thermal decomposition of $\mathrm{AN}$, which resulted in the appearance of the fourth DSC peak. Depending on the AN provenance a maximum was recorded in a range of $265-281^{\circ} \mathrm{C}$. For all samples, the phase IV $\rightarrow$ phase III transformation might be suppressed by the addition of magnesium to AN. In the case of AN-PP7 and AN-PP8, magnesium presence could be explained by the chemical composition of the coating agent. In the case of AN-F, magnesium was an essential component of fertilizer due to its fundamental property which is a plant nutrient.

All recorded transition peaks comprise the phase transition temperature presented in [26]. However, Chellappa et al. indicated major complexities in phase IV and phase III transition [27]. 
Lower decomposition temperature is specific to AN-PP. The appearance of TG curves depicted in Figures 3 and 4 indicated that mass loss was caused only by the evaporation of fuel oil from AN. For comparison, the TG curves present in Figure 9. Shows that full mass loss corresponds distinctly to the decomposition of AN. Additionally is preceded by the desorption of FO from the AN surface, pores and FO monolayer, all in the correct order. However, according to [5], the distinction between FO evaporation from pores and monolayer is not well known. In case of AN-F + FO excess, a significant mass loss (referenced in the pale blue line) begins at ca. $100{ }^{\circ} \mathrm{C}$. However in case of AN-PP7 + FO excess and AN-PP8 + FO excess the mass loss begins at higher temperature of ca. $177^{\circ} \mathrm{C}$, Figure 8 The lower absorption ratio of AN-F might explain the observed phenomenon. Nevertheless, further study will be performed.

In the case of ANFO, the introduction of fuel oil into AN can result in complex reactions, which may be explained by the role of nitrate ion as an oxidizing agent and ammonium ion which is responsible for the reduction reactions [15]. It was established that the addition of wax-coating to the pure AN might cause the ignition temperature in the range of $177-232{ }^{\circ} \mathrm{C}$, however charring begins at $107^{\circ} \mathrm{C}[15,28]$. Other fuel components like paper and wood lead to the autoignition of fuel component at ca $250{ }^{\circ} \mathrm{C}$. Hence, at the temperatures below $250{ }^{\circ} \mathrm{C}$ the reactivity of the fuel component should not take place $[15,29]$. On the other hand, $\mathrm{Wu}$ and Zavarin reported the presence of a strong exothermic peak at $184-212{ }^{\circ} \mathrm{C}$. It was indicated that the decomposition of pure AN-PP occurs according to the following reaction (1):

$$
\mathrm{NH}_{4} \mathrm{NO}_{3} \rightarrow \mathrm{N}_{2} \mathrm{O}+2 \mathrm{H}_{2} \mathrm{O}
$$

On the other hand, in the case of the AN-F with the addition of $3.0 \%$ wt. coating, the absence of reactivity was found. Babrauskas and Leggett indicated that in the available literature associated with the ANFO chemistry, no research concerning the influence of organic contaminants on the AN decomposition was published $[15,28]$. Fedroff et al. have indicated that ammonium nitrate (V) decompose above $230^{\circ} \mathrm{C}$. However above $325^{\circ} \mathrm{C}$ it may deflagrate [30]. If is confined and the critical diameter is meet, AN may explode between $260-300^{\circ} \mathrm{C}$. Neither of this process were recorded.

\section{Conclusions}

Analysis of SEM micrographs indicated that the presence of wrinkles describes both AN-PP7 and AN-PP8 prills and the studied AN-PP surfaces having pores. Similar findings took place for the photos made in the cross-section model. The wrinkle morphology was observed on the whole surface of the prill. Different effects were found for the AN-F granule, which surface was rather plain with a small number of deformations. All observed differences in the morphology influenced the absorption ratio of AN.

The appearance of DSC curves shows small differences between desorption ratios of AN-PP7 and AN-PP8. The influence of AN-PP prill diameter on the ANFO's properties, e.g., detonation velocity, the heat of explosion or critical diameter should be further determined to select appropriate non-ideal material to specific geological conditions properly.

From DSC results, it may be concluded that the presence of fuel oil did not affect the crystallographic transformation temperatures.

Analysis of TG curves led to the conclusion that decomposition of AN is mainly responsible for the mass loss. Furthermore, it was found that the AN decomposition process occurred in the concrete temperature range depending on the AN provenance. For AN-F and AN-PP samples, the decomposition begun at ca. $100^{\circ} \mathrm{C}$ and $177^{\circ} \mathrm{C}$, respectively. Observed differences can be explained by a lower absorption ratio of AN-F to AN-PP7 and AN-PP8 analogues.

In this paper, presented and discussed TG/DSC and SEM results showed clearly that the provenance of AN is essential for the production of ANFO. Analysis of the experimental data prompted us to the further application of AN-PP as a precursor for the ANFO manufacture. 
Author Contributions: Conceptualization, A.B.; methodology, A.B.; validation, Ł.K., B.D.N.; formal analysis, A.B.; investigation, A.B., Ł.K., M.D., M.T. (Michał Twardosz), M.T. (Maciej Tatko), B.D.N.; resources, A.B., Ł.K., B.D.N.; writing-original draft preparation, A.B., Ł.K., M.D., M.T. (Michał Twardosz), M.T. (Maciej Tatko); writing一review and editing, A.B.; visualization, A.B., Ł.K.; supervision, A.B. All authors have read and agreed to the published version of the manuscript.

Funding: The authors wish to thank for the financial support no. 16.16.100.215 received from The Faculty of Mining and Geoengineering at the AGH University of Science and Technology in Krakow. SSE Poland Sp. z o.o. is greatly acknowledged for delivering the AN-PP samples.

Acknowledgments: The authors wish to thank for financial support no. 16.16.100.215 received from The Faculty of Mining and Geoengineering at the AGH University of Science and Technology in Krakow. SSE Poland Sp. z o.o. is greatly acknowledged for delivering the AN-PP samples.

Conflicts of Interest: The authors wish to confirm that there are no known conflict of interest associated with this publication, and there has been no significant financial support for this work that could have influenced its outcome.

\section{References}

1. Glauber, J.R. Pharmacopoea Spagyrica; Johannes Jansson: Amsterdam, The Netherlands, 1654.

2. Shearon, W.H., Jr.; Dunwoody, W.B. Ammonium nitrate: A staff-industry collaborative report. Ind. Eng. Chem. 1953, 45, 496-504. [CrossRef]

3. Landucci, G.; Reniers, G.; Cozzani, V.; Salzano, E. Vulnerability of industrial facilities to attacks with imporivised devices aimed at triggering domino scenarios. Reliab. Eng. Syst. Saf. 2015, 143, 53-62. [CrossRef]

4. European Commission. Regulation (EC) No 2003/2003 of the European Parliament and of the Council of 13 October 2003 Relating to Fertilisers; European Commission: Brussels, Belgium, 2003.

5. Kwok, Q.S.M.; Jones, D.E.G. Thermodesorption studies of ammonium nitrate prills by high-resolution thermogravimetry. J. Therm. Anal. Calorim. 2003, 74, 57-63. Available online: https://link.springer.com/ article/10.1023/A:1026317517373 (accessed on 1 September 2019). [CrossRef]

6. Biessikirski, A.; Kuterasiński, Ł.; Dworzak, M.; Pyra, J.; Twardosz, M. Comparison of structure, morphology and topography of fertilizer-based explosives applied in the mining industry. Microchem. J. 2019, 144, 39-44. Available online: https://www.sciencedirect.com/science/article/pii/S0026265X18305162 (accessed on 5 September 2019). [CrossRef]

7. Viktorov, S.D.; Frantov, A.E.; Lapikov, I.N.; Andreev, V.V.; Starshinov, A.V. Effect of microstructure of ammonium nitrate granules on the detonability of composite propellants based on it. Combust. Explos. Shock Waves 2016, 52, 727-731. Available online: https://link.springer.com/article/10.1134/S0010508216060137 (accessed on 1 June 2020). [CrossRef]

8. Lotspeich, E.; Petr, V. The characterization of ammonium nitrate mini-prills. In Dynamic Behavior of Materials, Proceedings of the 2014 Annual Conference on Experimental and Applied Mechanics, Greenville, SC, USA, 2-5 June 2014; Song, B., Casem, D., Kimberley, J., Eds.; Springer: Cham, Switzerland, 2015; Volume 1, pp. 319-325. Available online: https://link.springer.com/book/10.1007\%2F978-3-319-06995-1 (accessed on 5 September 2019).

9. Elzaki, B.I.; Zhang, Y.J. Surface modification of ammonium nitrate by coating with surfactant materials to reduce hygroscopicity. Def Technol. 2019, 15, 615-620. Available online: https://www.sciencedirect.com/ science/article/pii/S2214914718305312 (accessed on 1 June 2020). [CrossRef]

10. Biessikirski, A.; Kuterasiński, Ł. Research on Morphology and Topology of ANFO Based on Various Types of Oxygen Component; Wydawnictwa AGH: Kraków, Poland, 2018. Available online: https://www.wydawnictwoagh.pl/RESEARCH-ON-MORPHOLOGY-AND-TOPOLOGY-OF-ANFOBASED-ON-VARIOUS-TYPES-OF-OXYGEN-COMPONENT;s, karta,id,1298 (accessed on 1 June 2020).

11. Miyake, A.; Takahara, K.; Ogawa, T.; Ogata, Y.; Wada, Y.; Arai, H. Influence of physical properties of ammonium nitrate on the detonation behavior of ANFO. J. Loss Prev. Process 2001, 14, 533-538. [CrossRef]

12. Rao, K.V.R.; Hariharan, P.L.; Jagannathan, K.; Yoganarasimhan, S.R. Scanning electron microscopy of ammonium nitrate prills in relations to their application in ammonium nitrate fuel oil systems. Fuel 1989, 68, 1118-1122. Available online: https://www-1sciencedirect-1com-1000027zz0057.wbg2.bg.agh.edu.pl/science/ article/pii/0016236189901816 (accessed on 1 May 2020). 
13. Chaturvedi, S.; Dave, P.N. Review on Thermal Decomposition of Ammonium Nitrate. J. Energetic Mater. 2013, 31, 1-26. Available online: https://www.tandfonline.com/doi/abs/10.1080/07370652.2011.573523? journalCode=uegm20 (accessed on 1 May 2020). [CrossRef]

14. Berthelot, M. Explosives and Their Power; John Murray: London, UK, 1892.

15. Babrauskas, V.; Leggett, D. Thermal decomposition of ammonium nitrate. FAM Fire Mater. 2020, 44, $250-268$. [CrossRef]

16. Oommen, C.; Jain, S.R. Ammonium nitrate: A promising rocket propellant oxidizer. J. Hazard. Mater. 1999, 67, 253-281. [CrossRef]

17. Gunawan, R.; Freij, S.; Zhang, D.; Beach, F.; Littlefair, M. A mechanistic study into the reactions of ammonium nitrate with pyrite. Chem. Eng. Sci. 2006, 61, 5781-5790. Available online: https://www.sciencedirect.com/ science/article/pii/S0009250906002995 (accessed on 1 May 2020). [CrossRef]

18. Djerdjev, A.M.; Priyananda, P.; Gore, J.; Beattie, J.K.; Neto, C.; Hawkett, B.S. The mechanism of the spontaneous detonation of ammonium nitrate in reactive grounds. J. Environ. Chem. Eng. 2018, 6, 281-288. Available online: https://www.sciencedirect.com/science/article/pii/S2213343717306425 (accessed on 1 May 2020). [CrossRef]

19. Kaniewski, M.; Hoffmann, K.; Hoffmann, J. Influence of selected potassium salts on thermal stability of ammonium nitrate. Thermochim. Acta 2019, 678, 1-10. Available online: https://www.sciencedirect.com/ science/article/abs/pii/S0040603119303016 (accessed on 1 May 2020). [CrossRef]

20. Han, Z.; Schdeva, S.; Papadaki, M.I.; Mannan, M.S. Ammonium nitrate thermal decomposition with additives. J. Loss Prev. Process 2015, 35, 307-315. Available online: https://www.sciencedirect.com/science/article/abs/pii/ S0950423014001703 (accessed on 1 May 2020). [CrossRef]

21. Oxley, J.C.; Smith, J.L.; Rogers, E.; Yu, M. Ammonium nitrate: Thermal stability and explosivity modifiers. Thermochim. Acta 2002, 384, 23-45. [CrossRef]

22. Han, Z.; Schdeva, S.; Papadaki, M.I.; Mannan, M.S. Calorimetry studies of ammonium nitrate-Effect of inhibitors, confinement, and heating rate. J. Loss Prev. Process 2015, 38, 234-242. Available online: https: //www.sciencedirect.com/science/article/abs/pii/S0950423015300486 (accessed on 1 May 2020). [CrossRef]

23. Biessikirski, A.; Wądrzyk, M.; Janus, R.; Biegańska, J.; Jodłowski, G.; Kuterasiński, Ł. Study on fuel oils used in ammonium nitrate-based explosives. Przem. Chem. 2018, 97, 457-462. Available online: http://www.sigmanot.pl/publikacja-112770-badanie-ciek\%C5\%82ych-sk\%C5\%82adnik\%C3\%B3w-palnych-stosowanychw-materia\%C5\%82ach-wybuchowych-opartych-na-azotanie-amonu-przemysl-chemiczny-2018-3.html (accessed on 1 May 2020).

24. Zawadzka-Małota, I. Wpływ Struktury i Składu Górniczych Materiałów Wybuchowych na Zawartość Toksycznych Składników w Gazach Postrzałowych. Ph.D. Thesis, GIG, Katowice, Poland, 2009.

25. Vargeese, A.A.; Joshi, S.S.; Krishnamurthy, V.N. Effect of method of crystallization on the IV-III and IV-II polymorphic transitions of ammonium nitrate. J. Hazard. Mater. 2009, 161, 373-379. Available online: https://www.sciencedirect.com/science/article/abs/pii/S0304389408004949 (accessed on 1 May 2020). [CrossRef]

26. Xu, Z.-X.; Fu, X.-Q.; Wang, Q. Phase stability of ammonium nitrate with organic potassium salts. Cent. Eur. J. Energetic Mater. 2016, 13, 736-754. [CrossRef]

27. Chellappa, R.S.; Dattelbaum, D.M.; Velisavljevic, N.; Sheffield, S. The phase diagram of ammonium nitrate. J. Chem. Phys. 2012, 137, 064504. [CrossRef] [PubMed]

28. Macy, P.F.; Dudderar, T.D.; Reese, E.F.; Eriksen, L.H. Investigation of Sensitivity of Fertilizer Grade Ammonium Nitrate to Explosion; Technical Report Serial No. 1658; Picatinny Arsenal: Dover, NJ, USA, 1947.

29. Babrauskas, V. Fire Science Publishers/Society of Fire Protection Engineers; Ignition Handbook; Fire Science Publishers: Issaquah, WA, USA, 2003.

30. Fedoroff, B.T.; Aaronson, H.A.; Sheffield, O.E.; Reese, E.F.; Clift, G.D.; Dunkle, C.G.; Walter, H.; McLean, D.C. Encyclopedia of Explosives and Related Items; US Department of the Army, Picatinny Arsenal: Dover, NJ, USA, 1960; Volume 1.

(C) 2020 by the authors. Licensee MDPI, Basel, Switzerland. This article is an open access article distributed under the terms and conditions of the Creative Commons Attribution (CC BY) license (http://creativecommons.org/licenses/by/4.0/). 